Arteterapia. Papeles de arteterapia y educación para inclusión social ISSN-e 1988-8309

https://dx.doi.org/10.5209/arte.62574

\title{
Grupos de tabaco, nuevos caminos para la arteterapia. Experiencia cognitivo-conductual con arteterapia en un Centro Municipal de Salud Comunitaria $^{1}$
}

Pablo García Bartolomé2

Recibido: 1 de diciembre de 2018 / Aceptado: 15 de mayo de 2019

Resumen. Cada vez más la arteterapia consolida y amplía su presencia en el ámbito de la salud abordando problemáticas de importancia social. La inclusión de la arteterapia en tratamientos grupales para la deshabituación tabáquica es novedosa dentro de los servicios públicos de salud. De ahí que los objetivos iniciales de este estudio estuvieran en buscar una forma complementaria de colaboración con el tratamiento psicológico-farmacológico, analizar las funciones psicológicas y autorreguladoras de las imágenes internas, y considerar la arteterapia como un posible factor de adherencia al tratamiento de tabaquismo. La combinación de arteterapia y la terapia cognitivo-conductual hizo posible converger los objetivos de los dos tipos de intervenciones. Se ha empleado una metodología mixta de investigación (MMI) de carácter exploratorio, con recogida y análisis de los datos mediante instrumentos cualitativos y cuantitativos. Se invitó a participar voluntariamente a 14 fumadores de un grupo de tabaco en un programa de 9 semanas. Los resultados muestran que aquellos miembros del grupo de tabaco que continuaron y completaron el tratamiento con éxito habían asistido al programa complementario de arteterapia para fumadores. No obstante, cabe decir que hubo usuarios de arteterapia que abandonaron el grupo de tabaco antes de finalizarse. El análisis de las obras y la observación del desarrollo de las sesiones informa positivamente sobre algunas funciones - psicológicas- del arte como la memoria, la esperanza, la aceptación del dolor, el autoconocimiento, y el reequilibrio. Una entrevista grupal abierta al finalizar el tratamiento mostró que la motivación, el aprendizaje de un nuevo lenguaje y la toma de perspectivas fueron lo más destacado del programa. Mientras que el cuestionario de evaluación del programa reveló sentimientos de relajación, y, respaldó las vías de la adherencia y el autoconocimiento ya observadas con otros análisis.

Palabras clave: fumadores; adherencia; autorregulación; cognitivo-conductual; salutogénesis.

\section{[en] Smoking groups therapy, new paths in art therapy. A cognitive behavioral art therapy study in a community municipal health centre}

\footnotetext{
Abstract. Nowadays, art therapy increasingly consolidates and expands its presence in the field of health, with the capacity to affront relevant issues in our societies. The inclusion of art therapy in group therapies for smoking cessation is novel within the public health services. The initial objectives of this study were to seek a complementary form of collaboration within the psychological-pharmacological treatments in progress, to analyze the psychological and self-regulatory functions of internal images, and to consider

1 Investigación realizada como alumno en prácticas del Máster de Arteterapia y Educación Artística para la Inclusión Social.

2 Psicólogo en Educación y Desarrollo Evolutivo, N. ${ }^{\circ}$ Col. M-33251. Arteterapeuta, Titulado Máster Oficial. Universidad Complutense de Madrid. Eco-Art Therapist in training, Project to Nature Connect (USA). Beca de Arte y Cuidados frente a los malestares de la vida cotidiana en Madrid Salud-Madrid Ciudad de los Cuidados. Arteterapeuta en Centro Joven de Madrid

E-mail: pablog17@ucm.es
} 
art creation as a possible factor of adherence to smoking treatment. The combination of art therapy and cognitive-behavioral therapy made it possible to converge the objectives of the two types of interventions. A mixed research methodology (MMI) was used, with data collection and analysis through qualitative and quantitative instruments. Were invited to voluntarily participate in a 9-week program, the all 14 persons already involved in a tobacco group. The results showed that those members of the tobacco group who continued and completed the treatment successfully had attended the complementary art therapy program for smokers too. However, it must be said that there were also art therapy users that they abandoned the treatment before finishing. The analysis of the works and the observation of the development of the sessions inform positively on some functions - psychological- of art creation as memory, hope, acceptance of the pain, self-knowledge, and rebalancing. An open group interview at the end of the treatment showed that motivation, learning a new language and walking through other perspectives were the highlights of the program by the users. Moreover, evaluation questionnaire revealed subjetive feelings of relaxation, and other items supported the pathways of adherence and self-knowledge already observed with other analyzers.

Keywords: tobacco smokers; treatment adherence; self-regulation; cognitive-behavioral; salutogenic model.

Sumario. 1. Introducción. 2. Revisión de la literatura. Arte y tratamientos psicológicos. Arteterapia para grupos de tabaco. 3. Diseño de investigación. 4. Un programa de arteterapia dirigido para fumadores. 5. Resultados y discusión.

Cómo citar: Bartolomé, P. G. (2019) Grupos de tabaco, nuevos caminos para la arteterapia. Experiencia cognitivo-conductual con arteterapia en un Centro Municipal de Salud Comunitaria, en Arteterapia. Papeles de arteterapia y educación para inclusión social 14, 2019, 21-38.

\section{Introducción}

“QQué sentido tiene hacer arte para dejar fumar?” Esta pregunta fue recogida durante la última sesión de un programa de arteterapia para la deshabituación tabáquica. Es apreciable el valor reflexivo que la creación artística supuso para los usuarios. Y aunque el arte si puede ayudar como reconocerían los participantes, de fondo, se ponía en cuestión si posee la capacidad de frenar el consumo de tabaco en una persona fumadora de forma definitiva. Estos usuarios estaban cuestionándose el arte a la luz de un discurso medicamentoso de la intervención. Cierto es, que no es el arte ni un antagonista de la nicotina ni un sustitutivo de la misma. Eso es evidente. Entonces, cabe preguntarse qué ofrece el arte a aquellos fumadores y fumadoras que quieran dejarlo.

El tabaco es un producto obtenido a partir de la planta Nicotiana Tabacum. Consumido de forma habitual en forma de cigarrillos el tabaco comercial contiene más de 4.000 sustancias y, de ellas, al menos, 250 son perjudiciales para la salud (Becoña, Fernández del Río, López, Martínez, Martínez, y Rodríguez, 2014). Afortunadamente, cada vez existe mayor consciencia social sobre las consecuencias negativas de su consumo. Y es que los beneficios para la salud de dejar de fumar resultan evidentes. Al dejar de fumar se aumentará la esperanza y la calidad de vida y cualquier edad será buena para dejar de fumar. Los cambios, muchos, se observarán a corto y largo plazo. Por ejemplo la piel rejuvenece, la respiración se vuelve más amable, el riesgo de padecer enfermedades cardiovasculares y de cáncer a causa del tabaco se reduce (información médica en detalle sobre los beneficios de dejar de fumar en Pardell y Saltó, 2004). Motivos para no fumar hay muchos y los mejores, según el Comité Nacional para la Prevención del Tabaquismo, son aquellos que surgen de la propia persona (Salvador y cols., 2005). 
Aún así, el portal de salud virtual de la Comunidad de Madrid publicó en 2017 que algo más de una cuarta parte de la población entre 18 y 64 años eran fumadora habitual. En los Centros Municipales de Salud Comunitaria (CMSc) del Ayuntamiento de Madrid existe una oferta de programas saludables para la prevención y promoción de la salud, y entre ellos, dentro de la estrategia Barrios Saludables, figura el programa de prevención y control del tabaquismo ${ }^{3}$. Desde estos centros se está dando un impulso en los últimos años hacia un modelo salutogénico y de activos en salud. Se trata de una estrategia centrada no tanto en el problema como en la búsqueda de soluciones. Así, una estrategia sería potenciar los recursos y habilidades de los individuos y colectivos. Este sentir recoge las ideas de Antonosvky que entiende que los individuos oscilan entre ajustes y desajustes, en un continuo entre la salud y la enfermedad, y se les confiere una capacidad autorreguladora que es capaz de llevarles a la búsqueda de su propio equilibrio y su auto-curación. Habrá oportunidad más adelante al hablar del arte de recuperar estas ideas...

Afortunadamente, en los últimos años los servicios públicos de salud comienzan a introducir el arte como una herramienta saludable. En estas actuaciones se agrupa la presente intervención de arteterapia para grupos de tabaco. Por lo sabido, sería la primera intervención arteterapéutica que consta en las guías clínicas con este colectivo en nuestro país (E. Becoña, comunicación personal, diciembre 27, 2017).

Al inicio de esta investigación con la llegada al CMSc la pregunta inicial fue sobre todo de tipo pragmático. La preocupación no estuvo, como se vería, en preguntarse si el arte sirve para dejar de fumar, sino, en cómo sería la forma de colaborar con el programa de deshabituación tabáquica vigente en el centro. Era conocido que los servicios ofertados para fumadores en los CMSc consisten en programas clínicos multimétodo, una combinación psicológica y farmacológica, de tendencia cognitivoconductual con una proyección social y comunitaria a su vez (Herrero y Moreno, 2004). Cuestión ésta y otras que se plantean a continuación.

\section{Revisión de la literatura}

\section{Arte y tratamientos psicológicos}

En tabaquismo los tratamientos psicológicos cognitivo-conductuales (TCC) tienen en cuenta factores fisiológicos, psicológicos y sociales del hábito de fumar. Pueden considerarse tratamientos de primera línea (Becoña, Míguez, Fernández, López, 2010). Quizás, el aspecto más aprovechado por la arteterapia cognitivo-conductual (ATCC) sea el cognitivo. En el libro Cognitive Behavioral Art Therapy, la arteterapeuta Marcia L. Rosal (2018) destaca la creación artística como generadora de activación cognitiva (p. 7). Cabe pensar entonces que las y los arteterapeutas próximos a la TCC emple descubriendo, además, la arteterapia para el desarrollo y mejora de habilidades, la resolución de problemas, la toma de decisiones, lograr mayor flexibilidad psicológica, explorar perspectivas, entre otras. Pero además el arte puede ser visto también como conducta. Desde las aproximaciones que llevan a Kaplan (2000) al estudio del proceso de creación artística llegan aires frescos que conducen a una perspectiva científica y evolutiva a la par que humanista. Kaplan, que analiza las

Según la página web del Ayuntamiento de Madrid 
ideas del pensamiento de la antropóloga Helen Dissanayake, expone que para esta autora el arte sería algo más que una mera respuesta estética en pro de la supervivencia. La conducta artística, si resulta aceptable traducir así al castellano, aporta un modo especial de hacer al comportamiento humano (Kaplan, 2000, pp. 57-59). Esta conducta especial recubre de valor significativo los acontecimientos importantes en la vida de una persona así como también marcaría ciertos períodos de transición y de cambio. Cabe asociar, pues, dar a esta forma ritual de aproximarse al arte y la creación artística una función que rescata y preserva la memoria (De Bottom y Armstrong, 2013). Esta cualidad mnemónica del arte, recuerdo-imagen que perdura, no es el único encuentro entre arte y psicología reflejado en la obra de estos autores. De Bottom y Armstrong (2013, pp. 8-61) clasificaron, al menos, siete funciones atribuidas al arte. Esta lista abre la puerta a otros paralelismos con los objetivos planteados desde las técnicas psicológicas en intervención con fumadores. En la lista se encuentran: la esperanza ante las posibilidades de cambio -véase una motivación para dejar de fumar-, la aceptación del dolor y la tristeza, el reequilibrio emocional, el autoconocimiento -véase como una consecuencia de la técnica de autoobservación-, el crecimiento -llevado al desarrollo de habilidades y mejoría del individuo-, y la apreciación como agente de cambio de rutinas y de hábitos - una mirada satisfactoria de la vida cotidiana sin el tabaco- .

Pero, ¿cuáles o qué funciones cumple la arteterapia? O dicho de otro modo... ante la posibilidad de introducir la arteterapia en un tratamiento para fumadores de un programa sanitario de este tipo cuáles son las aportaciones del arte y la arteterapia a la terapia convencional. En torno a esto, la arteterapeuta Judith. A. Rubin (2005, pp. 20-33) defiende la inclusión del arte como parte del proceso terapéutico por su ayuda para comunicar, aliviar y afrontar. El arte posee una capacidad natural para comunicar. Es un lenguaje para llegar a expresar aquello no alcanzado en las palabras, una comunicación de marcas y signos que precede al surgimiento del lenguaje mismo. La autora también resalta la importancia que tiene el sistema visual en nuestro pensamiento y la capacidad de síntesis de la imagen para comunicar conceptos e ideas. Otro motivo para utilizar el arte en terapia sería el rol que la interacción con los materiales artísticos tiene en la desinhibición, la liberación de tensiones y el intercambio verbal dentro de la terapia. El arte añadido a la terapia desatasca, modula, acelera... los procesos del tratamiento. Ya por último, el arte está al servicio del usuario como un modo alternativo de afrontamiento de problemas. Otra arteterapeuta, Shirley Riley (2001, pp. 1-33), destacó la habilidad del arte como impulsor de los procesos internos en la persona. En esta ocasión las marcas en el dibujo devienen en huellas del presente que revelan hechos del interior del sujeto recuperando la idea de la marca y el signo como elementos de comunicación esta vez con uno mismo. Es una imagen que se torna consciente permitiendo ser examinada, discutida junto al arteterapeuta y situar a la persona, quizás, en el camino del cambio. Tanto es así que la aportación, y la diferencia, más significativa de la arteterapia respecto de la terapia convencional-verbal resida en el trabajo terapéutico a partir de imágenes. Por otro lado, López-Fernández Cao (1998) invita a no quedarse en una lectura parcial de las imágenes sino a abrirse a una mirada plural y polisémica de su forma y contenidos. Esta autora sugiere que la comunicación con imágenes permite significados retóricos, que facilitan lo no accesible, y situaría la terapia en un contexto/realidad personal y social concretos. 
En conclusión, se trata de concretar de qué forma sería usado el arte en las sesiones con fumadores, a saber, no como un método diagnóstico sino como un medio de comunicación, de autoconocimiento, de cambio personal y de transformación social.

Desde esta línea de pensamiento es que se plantea añadir el arte como recurso terapéutico complementario para grupos de tabaco a través de la arteterapia. Revisando algunas autoras clave parece que no se ha comenzado a estudiar la eficacia de la arteterapia como tratamiento complementario hasta hace algunos años pero vendría siendo una práctica habitual de los arteterapeutas en el ámbito de la salud desde los inicios de la profesión (Rubin, 2005, p. 224). Lo frecuente, en estos casos, suele ser un tratamiento principal que recurre a la expresión artística como recurso extra para apoyar los progresos del paciente en terapia.

\section{Arteterapia para grupos de tabaco}

Defendidas algunas contribuciones que el arte y la arteterapia aportarían a los tratamientos clínicos en adelante se revisará el funcionamiento de los grupos de tabaco y cómo -o si es posible- adaptarse a este formato.

Lo primero que llama la atención de un grupo de tabaco es su finalidad. El objetivo y compromiso firme del paciente para dejar de fumar es condición, si acaso única, para unirse al grupo (Herrero y Moreno, 2004). Este tipo de terapia psicológica grupal o en grupo va dirigida a dar una respuesta a un problema concreto a diferencia de la terapia de grupo más próxima a las prácticas psicodinámicas (Becoña, Míguez, Fernández, López, 2010). Dicen los expertos que la terapia en grupo es especialmente útil con fumadores. En ellas el terapeuta asume el rol de dirigir a cada miembro del grupo hacia la mejoría de sus habilidades de afrontamiento para dar salida a la situación-problema. La clasificación de las intervenciones con grupos será muy cuidada también desde la arteterapia. En Liebmann (2004, p. 17) los grupos aparecen ordenados atendiendo a la acción del arteterapeuta. Según esta autora, el número y tipo de instrucciones que el arteterapeuta facilita será aquello que configure los grupos como más estructurados o menos estructurados. Comenta López $(2009$, p. 387) que esta directividad del arteterapeuta estará contrapuesta a la libre elección del usuario de temas, materiales, soportes... Volviendo a Liebmann y los grupos de arteterapia que esta autora denomina dirigidos a/centrados en un objetivo se identifica que: 1) tienen un programa de sesiones de corta duración; 2) están conducidos o liderados por el arteterapeuta; 3 ) utilizan temas con el fin de aproximarse más directamente a un problema concreto (2004, p. 15). Dos de las características, la guía del terapeuta y un objetivo claro del grupo, se han mencionado anteriormente.

En cuanto a la forma los grupos de tabaco se caracterizan por tener de media entre 5 y 7 sesiones, cada sesión puede durar desde 1 hasta 2 horas y recomiendan crear grupos poco numerosos de hasta 12 personas (Becoña, Míguez, Fernández, López, 2010). Los grupos en arteterapia suelen tener un tamaño similar (Liebmann, 2004, p. 29; López, 2009, p. 346). Algo más difícil de conciliar es el tiempo de duración de las sesiones. La extensión de ambos tratamientos seguidos podría alcanzar 4 horas, algo a considerar.

Por tanto, del análisis comparado de los grupos psicológicos y los grupos de arteterapia surgen argumentos para justificar un tipo de intervención arteterapéutica basada en grupos estructurados y centrados en un tema específico. Pero sin duda un respaldo para complementar los grupos de tabaco con arteterapia es su familiaridad 
con el formato grupal. Entre los arteterapeutas españoles el trabajo con grupos figuraría como el más frecuente (López, 2009, p. 386). No obstante, no es lo habitual que los grupos se orienten hacia objetivos tan específicos como sería dejar de fumar. Si se encuentran en la literatura grupos que exploran el autoconcepto, las relaciones personales o las inquietudes (López, 2009, p. 349). Esta forma indirecta de abordar temas-objetivo enfocada en potenciar los recursos de la persona recupera aquello inicialmente planteado en el modelo salutogénico y estará presente en la base del diseño de las sesiones luego planteadas.

En cuanto a cuestiones más específicas de la intervención con arteterapia queda tratar la selección de temas y el uso de los materiales. Las propuestas temáticas para cada sesión podrían inspirarse en el protocolo clínico. Así, la evidencia de la eficacia del método psicológico mostrará a la/el arteterapeuta los tiempos más idóneos para sugerir qué tipo de propuestas artísticas. Además, es recomendable nutrirse de la observación directa de las sesiones del grupo de tabaco para ampliar el conocimiento de la intervención. Como segunda cuestión, rescatar el aspecto psicológico presente en la relación con los materiales artísticos. Esto ha sido estudiado recientemente. En entrevistas realizadas a arteterapeutas expertos (Pénzes, van Hooren, Dokter, Smeijsters, y Hutschemaekers, 2014) se dio a conocer que la interacción con los materiales resulta un indicador de aspectos emocionales -rabia, ansiedad-, cognitivos -control-, y motivacionales -rechazo, insight-.

Finalmente queda pensar en la dinámica de las sesiones que, siguiendo la misma línea, se aproximaría más a aquellas de tipo estructurado. Las más frecuentes son aquellas de cuatro fases: warm-up ${ }^{4}$, creación artística, reflexión en grupo a partir de las imágenes creadas, y cierre (Case y Dalley, 2006; Liebmann, 2004, p. 33).

Se han puesto en común arte, arteterapia y psicología encontrando similitudes y conexiones que posibilitan una intervención mixta. Quedaría en el aire una última reflexión sobre si existen razones para pensar en nuevas formas de intervenir en el área de tabaquismo ¿Sería la arteterapia una opción para esta nueva realidad?

En los últimos años se han observado algunas novedades. Los programas clínicos de autoayuda se están llevando a cabo con resultados aceptables. Sobre ellos, es relevante el manejo de autoinstrucciones y el uso de materiales audio-visuales tales como imágenes, folletos, cine, internet... (Míguez, 2004). Por otro lado y teniendo en cuenta que no todas las personas recurren al tratamiento psicológico, investigadores españoles se han interesado por el fenómeno del autoabandono (Rosales-Nieto, y cols., 2016). Estos autores informan de un creciente porcentaje de personas que dejan de fumar por sí mismas y estudian sus características. No consistiendo la arteterapia ni en uno ni en otro son el autocuidado, la relación con nuevos medios de escucha y expresión, y el territorio del sí mismo lugares comunes para la arteterapia que orientan a favor de las intervenciones a través del arte para fumadores.

El objetivo principal de este estudio es diseñar y poner a prueba un programa de arteterapia que resulte complementario a los tratamientos psicológicos para fumadores. Los buenos resultados se esperan gracias al efecto terapéutico de las sesiones (relación terapéutica, materiales, temas), la atención prestada a las estrategias psicológicas, y a las funciones del arte como recurso terapéutico. Ya se han presentado

4 "Warm-up" es un término inglés que se traduce como calentamiento. Sería ésta una manera de diferenciar entre lo exterior y el grupo que va a comenzar. Un espacio para "soltar" a través del dibujo libre, actividades corporales, relajaciones, introducción de temas de interés, etc. 
razones para sostener la incorporación del arte y la arteterapia como parte de un programa multimétodo para dejar de fumar. Pues bien, se sabe que un factor para el éxito es la adherencia al tratamiento que ha sido directamente relacionada con el feedback de mejoría obtenido durante, al menos, la parte inicial del mismo (de la Llave, Buceta, y Pérez-Llantada, 2000). Lo que se plantea es que la creación de imágenes, y la autoobservación de los procesos artísticos, sustentarían esta hipótesis de la adherencia en la medida que funcionarían como elementos autorreguladores con información interna del progreso de la persona llevándola hacia el cambio (Nucho, 2003).

\section{Diseño de investigación}

Se partió de una situación concreta respondiendo a la llamada de un CMSc del Ayto. de Madrid para participar en los grupos de tabaco. Observación participante, reuniones y encuentros informales en el centro iniciaron el estudio dada la necesidad de conocer los grupos y sus objetivos, familiarizarse con el perfil de usuarios que acceden al programa, relacionarse con los profesionales al cargo, sentir el ritmo las sesiones, y aprender la metodología de intervención del centro. Este período de preintervención duró dos meses. Obviamente, con el apoyo de la dirección del centro, se abordaron cuestiones fundamentales para la intervención con arteterapia referidas al número de sesiones, su duración, frecuencia, número de asistentes, forma de participación, tipo de intervención, objetivos, contenidos, y materiales artísticos. Seguramente la decisión más crítica que se tomó al inicio fue la forma de intervenir. De manera consensuada con los profesionales en tabaquismo del centro se decidió incorporarse como tratamiento complementario al programa principal. En este punto, el enfoque de arteterapia cognitivo conductual (ATCC) sirvió de marco de referencia de la disciplina.

El diseño del programa de intervención se apoyó en cuatro pilares: (1) estudio de las guías del centro para el tratamiento clínico de fumadores; (2) observación directa y participante de las sesiones; (3) conocimientos integrados de la TCC y la ATCC; (4) investigaciones relevantes en tratamientos de tabaquismo ${ }^{5}$. El modo de proceder del investigador fue creativo. El reto consistió en elaborar un programa de 9 sesiones, con una selección de temas para cada sesión y siguiendo en paralelo el ritmo del programa convencional con el objetivo de ampliar los recursos y las opciones de las usuarias y los usuarios.

Se recurrió a la metodología mixta de investigación (MMI) para combinar instrumentos de recogida y análisis de datos cualitativos y cuantitativos (Tashakkori y Teddlie, 1998).

\section{Participación}

Las personas fumadoras se incorporaron al programa de arteterapia de forma voluntaria. Se promocionó el proyecto mediante panfletos que describían sus características y objetivos, que la institución se encargó de difundir entre sus usuarios del centro. En este grupo piloto todos los participantes procedían de un mismo grupo

5 Se tomó la decisión de no incluir un enfoque en adicciones dado que la estrategia de los CMSc en tabaquismo sigue una línea diferente. 
de tabaco de 14 adultos fumadores. De este grupo principal 9 de sus miembros accedieron a rellenar un cuestionario inicial y, sólo, 7 personas ${ }^{6}$ comenzarían con las sesiones de arteterapia. Hubo 4 mujeres y 3 hombres con una media de edad de 59,6 años.

\section{Recogida de datos}

Para la parte cualitativa sirvió un diario de campo donde registrar las sesiones con notas instantáneas, expandidas, autoobservaciones y reflexiones de investigador (Va1les, 1999, pp.168-173). Además, una observadora externa del equipo del CMSc colaboró en varias de las sesiones.

Al término del programa, durante la última sesión, se realizó una entrevista grupal abierta para recoger las opiniones de los usuarios, en retrospectiva, sobre las obras creadas más una valoración de las sesiones y de su utilidad. También respondieron un cuestionario de tipo Likert diseñado para la evaluación de los puntos más importantes de la intervención en una escala de 1 a $4^{7}$. En este cuestionario los usuarios puntuaban 7 aspectos a cerca de los esperados beneficios del tratamiento:

- $\quad$ el grado de apoyo de la arteterapia para continuar en el tratamiento hasta el final (hipótesis de adherencia),

- la relajación,

- el autoconocimiento del propio problema,

- el autoconocimiento de si mismos,

- los recursos de afrontamiento adquiridos,

- la gestión de las emociones,

- e influencia percibida en la decisión para dejar de fumar asociada a la participación en el grupo de arteterapia.

\section{Instrumentos de análisis}

Cualitativos. En el diario de campo se utilizó un análisis de texto libre (FernándezNuñez, 2004) para la evaluación del diseño del programa inspirado en categorías extraídas del manual de arteterapia Artful Therapy (Rubin, 2005, pp. 51-66). De sus registro en sus diarios el arteterapeuta atendería a: reacciones y relaciones con los materiales artísticos; cómo fue recibida y entendida cada tarea; interacciones con el terapeuta; procesos creativos y psicológicos; nivel de actividad; evolución y cambios a lo largo de la terapia. Otro tipo de análisis dirigido a responder a cuestiones iniciales aplicó las 7 funciones del arte descritas en el libro Art as therapy (De Bottom y Armstrong, 2013) a las obras y sus procesos. La justificación de este análisis múltiple estuvo en reforzar la idea de los beneficios psicológicos del programa de arteterapia.

Cuantitativos. Se contabilizó la asistencia a las sesiones de arteterapia para comparar la asistencia al grupo de tabaco y a las informaciones de tipo cualitativo. Además, se utilizó un cuestionario de evaluación subjetiva ad hoc para evaluar los resultados de las sesiones.

La mitad de los usuarios del grupo de tabaco.

Nada, poco, bastante o mucho. 


\section{Un programa de arteterapia dirigido para fumadores}

Novel-9 es un programa piloto de arteterapia para dejar de fumar aunque no se estableció éste como el objetivo principal en tanto que ofrece un espacio terapéutico complementario, de comunicación alternativa y promotor del cambio. Así, el punto central de la intervención fue impulsar los recursos de los usuarios ${ }^{8}$. Respaldado por la práctica psicológica, la adaptación de las técnicas psicológicas a términos artísticos-terapéuticos se conduce de manera flexible (Czamanski-Cohen et al., 2014). La selección de los temas, las técnicas artísticas y los materiales permiten ser modificados/reemplazados si bien su aplicación ha sido previamente estudiada atendiendo a las técnicas psicológicas empleadas en cada fase. Por eso, se aconseja a el/la arteterapeuta que vaya a intervenir no perder de vista el recorrido y los tiempos de este tipo de tratamientos - preparación, abandono, mantenimiento (Becoña, 2003).

La propuesta inicial de 9 sesiones hubo de ser modificada eliminando la primera de las sesiones al comienzo del grupo, de forma que el grupo de arteterapia comenzó una semana después que el grupo de tabaco. Además, la primera y la última sesión de arteterapia tuvieron un carácter especial (Rubin, 2005, p. 127). A continuación se describe el diseño del programa sesión a sesión:

Sesión 1. "Yo en mis bolsillos". Sesión de presentación. No se necesita de ningún material artístico. Al contrario, los usuarios eligen objetos personales como si fueran objetos artísticos que les presentan ante el grupo. Además, en una segunda parte de la sesión se pueden ofrecer objetos y materiales no-artísticos como medio de exploración y estimulación sensorial. En ambos casos, se incentivará la sensibilidad al lenguaje simbólico y metafórico artístico. Sesión 2. "Línea de vida del fumador". A través de la pintura el usuario trabaja sobre su historia de vida ${ }^{9}$ (completa, parcial o puntual) en relación al tabaco. Se ofrece la alternativa de abordar el problema desde el presente representando, de forma libre, el consumo de tabaco a lo largo de un día cualquiera ${ }^{10}$. Los materiales son de dibujo y pintura (rotuladores y lápices de colores, acrílicos y pinceles, ceras duras). Sesión 3. "Las excusas". En este ejercicio se pide a los usuarios representar en el dibujo, a través de la desinhibición de la mano, cómo es una excusa y cómo es una afirmación. La propuesta plantea una revisión de la relación entre los modos de hacer -hábitos- y las atribuciones. El material de dibujo está restringido a la pintura acrílica, en este caso aquel de menor preferencia, una exposición simbólica a la incapacidad de elegir y tomar decisiones. Sesión 4. "Las emociones". A partir de una discusión grupal previa sobre las emociones básicas y las emociones que afectan a una persona fumadora cada usuario/a representa en la mitad de la hoja una emoción seleccionada. Después, en la otra mitad de la hoja, se transforma dicha emoción en placentera, manejable, explorando sentir lo opuesto, recorriendo sus diferentes grados de intensidad... según cada caso ${ }^{11}$. Los materiales utilizados para esta sesión son de pintura y dibujo. Sesión 5. "Bienestar". Por encima del período crítico del tratamiento ("el día D dejar de fumar"), se quiere invitar a los usuarios a autogenerar sensaciones y pensamientos positivos. La relajación a partir del contacto directo con el material, en esta ocasión arcilla roja, guía el pro-

\footnotetext{
Mediante los objetivos que aparecen en "Recogida de datos"

Anámnesis.

Análisis funcional de la conducta.

Poniendo en relación emoción, pensamiento y acción (Terapia Racional Emotivo Conductual).
} 
ceso creativo. El arteterapeuta ofrece pautas de autorregulación a través del diálogo con el material, la obra y el entorno. Sesión 6. "Lobo... ¿cuál es tu bestia?”. Alcanzada la recta final del tratamiento es probable que aparezcan situaciones/estímulos externos que provocan miedo, vulnerabilidad, inseguridad y capaces de apartar del objetivo deseado. A través de la exposición segura que propone el medio artístico se afrontan condiciones aversivas encarnadas en la simbología animal. Esta práctica se enfoca en desarrollar habilidades de autocontrol y afrontamiento. En esta ocasión se fomenta que sea la persona quien se involucre en la decisión de elegir entre todos los materiales utilizados anteriormente el más apropiado para ella. Sesión 7. "Contrapublicidad". La información exterior ejerce mucha influencia sobre las personas. Se trata de crear un anuncio publicitario que refleje los propios valores, las intenciones, la reivindicación o el empoderamiento del individuo. Se utilizan como técnicas el collage y el recurso de adaptar refranes populares; parafrasear un refrán como indicador de que los viejos hábitos y costumbres arraigadas no dejan de ser modificables $^{12}$. Esta sesión tiene como objetivo impulsar la autoestima como fortaleza para mantener la abstinencia sin tabaco y hacerse fuerte ante la sugestión externa. Sesión 8. "Cierre". Un último momento para hacer balance de lo recorrido en sesiones anteriores terminando el grupo con una entrevista abierta y el ritual de la revisión/entrega de las obras realizadas (Rubin, 2005, p. 127)

\section{Resultados y discusión}

Un resumen de las observaciones más concluyentes registradas en el diario de campo se pueden leer en la Tabla 1 (Anexo) (Rubin, 2005, pp. 55-66). El análisis básico de las sesiones, el de su estructura, será de necesario tránsito para una evaluación del procedimiento de la intervención. En general, la relación de los usuarios con la arteterapia se caracterizó por una mezcla de desconocimiento y distanciamiento. Hubo rechazo inicial a pintar y sorprendió entre los usuarios que se les hablase de arte. No se percibió igual ante los referentes del programa tan disponibles y optimistas a las propuestas. Las dudas de los usuarios permanecerían hasta el final, si bien poco a poco comenzaron a poder expresarse y alcanzaron auténticos momentos de creación personal e intercambios ya avanzado el programa. Los diálogos se apoyaron en las imágenes creadas consolidando su valor como medio terapéutico.

La estructura cerrada del grupo, sesión a sesión, no obstaculizó el avance del proceso terapéutico individual. Temas, asuntos pendientes, cuestiones surgidas durante sesiones previas... reaparecían en creaciones posteriores. Por ejemplo, se podrían comentar algunos casos que reflejan estas relaciones de los usuarios con el proceso arteterapéutico. R (72) en la quinta sesión retrocedió hacia un ejercicio autobiográfico pendiente. Llama la atención que $\mathrm{R}$ fuera el único de los usuarios que en la sesión 2 eligiera observar su día a día mientras sus compañeros optaban por revisar su relación con el tabaco en su memoria biográfica. JL (67) se sentía más cómodo a partir de la quinta sesión cuando empezamos a utilizar arcilla. La fluidez se notaba en el número de obras producidas casi sin esfuerzo lejos de los bloqueos iniciales con la pintura. Coincidía además con el momento en que JL había dado el paso de dejar el tabaco. Durante aquella sesión el objetivo era encontrar relajación a través

12 Adaptación aplicada a través del arte del trabajo terapéutico en modificación de creencias. 
del contacto con el material y el tema representado en la obra de JL fue la comida. El apetito suele aumentar en las personas que dejan el tabaco y el fumador tiene la sensación que la ingesta de alimentos rebaja esa ansiedad alimenticia. ¿Representación del peligro o simplemente representación del presente, de su presente?. Una de las piezas del bodegón de JL fue una barra de pan. Ya en la siguiente sesión, JL trabajó de nuevo la arcilla. En esta ocasión representó a la serpiente como animal simbólico de sus miedos (estímulos del entorno). En ambos casos se repite una forma de barro marrón que cabe en la mano, cilíndrica y alargada... JL había sido fumador de $p u$ ritos hasta el momento del tratamiento.Ya en la última sesión JL, que había estado muy escéptico todo el proceso, reconoció sentirse más satisfecho de sus últimas creaciones que de las primeras. De nuevo su obra expresaba un sentimiento interno, de autoeficacia, que recogía el momento presente del éxito del tratamiento.

Se concluye que avanzar sesión a sesión con temáticas diferentes no es contrario a la evolución de un trabajo terapéutico personal continuado. El programa ha demostrado su flexibilidad pese a su carácter estructurado. Algunos usuarios pudieron expresarse acercándose a un estilo artístico personal propio, aun siendo mediante pequeños signos, garabatos o colores. Las obras mostraban unas señas de identidad que iban emergiendo a lo largo de las sesiones. Esta forma de dialogar con/a través de la imagen indica que aún en programas estructurados y directivos con un objetivo fijo se produce el encuentro con un nuevo lenguaje, uno propio, para comunicar, compartir experiencias, reflexionar, explorar nuevas perspectivas y dar respuestas ante su situación particular.

Proponer temas resulta beneficioso como idea inicial de arranque porque no saber qué hacer ni qué dibujar al comienzo es susceptible de generar aún mayor confusión a cerca de la presencia de la arteterapia en el tratamiento. Por contra, se observó que con el transcurso de las sesiones los usuarios parecieron menos dependientes, interpretando a su manera las actividades y entrando menos en conflicto por seguir unas instrucciones. Ahora bien, la decisión de utilizar propuestas dirigidas para cada sesión tuvo que ver también con las características de un grupo de tabaco, sus contenidos y la perspectiva psicológica del tratamiento.

Como se contempla en los registros de asistencia de la Tabla 2 (Anexo) parece que la intervención en paralelo de ambos grupos - de tabaco y de arteterapia- está justificada. Ahora bien, la adherencia al tratamiento es más visible al inicio y se va perdiendo con el transcurso de las sesiones tal como ocurriera en el estudio de de la Llave, Buceta, y Pérez-Llantada (2000). Durante la última fase se da que cuatro usuarios aguantan pero su asistencia comienza a ser irregular a partir de la sesión 5. En la sesión 7 sólo asiste una persona. Es decir, que la arteterapia fue un apoyo para las fases de preparación y de abandono (motivación) pero no tanto durante el mantenimiento (afrontamiento). Las razones que se manejan son varias. La duración del tratamiento que superó la media, la duración total de las sesiones por encima de las dos horas acumulándose el cansancio, superación del período crítico -dejar de fumar, reducción de los síntomas fisiológicos-, y/o rechazar exponerse a actividades introspectivas durante el frágil período inicial de la abstinencia.

Atendiendo al contenido de las obras, la preferencia por un estilo gráfico determinado no parece influida por las sugerencias e instrucciones. El ejemplo más claro de esto fue la autobiografía personal donde surgieron representaciones figurativas, abstracciones de color, mapas, recorridos gráficos. Entre los motivos representados por los fumadores se observó una ligera tendencia a representar el 
lado negativo del problema y la lectura en detalle de los significados mostró ambivalencias. Lo que para unos aparecía como positivo, para otros era negativo. Por ejemplo, un árbol simbolizó las raíces del tabaco difíciles de arrancar; en otro caso el árbol representaba la esperanza de una vida más saludable en el futuro. Signos recurrentes como la espiral sirvieron para referirse a sentimientos de angustia y de sentirse atrapado. Las gráficas de curvas oscilantes, ascendentes y descendentes, visibilizaban la inestabilidad de los estados emocionales. También hubo elementos representativos del universo del fumador como el cigarro, una máquina de respiración asistida o un café caliente en la mañana. A las imágenes es preferible acercarse con una mirada plural, se comentó en el marco teórico (López-Fernández Cao, 1998). De esta forma las imágenes conectan con significados personales, y a veces compartidos, resultando un proceso más completo para autoconocerse, para expresarse y para poder integrar lo que le ocurre. El café es el amigo inseparable del cigarrillo para muchos fumadores. Recuperamos la historia de una hospitalización con un testimonio que recuerda el peligro pasado y presente pero que protege para el futuro. Borrones de nubes grises indican nerviosismo... Es decir, se logró que los temas, seleccionados previamente con rigor, pertenecieran a uno y sirvieran a todos.

En la obras se observaron aspectos conductuales, cognitivos, fisiológicos y sociales. Contenidos de la vida de las personas y su entorno. No obstante, no se ha hecho un análisis de los cambios psicológicos individuales en cada sesión. Si se pidió rellenar unos cuestionarios de evaluación en la última sesión. En general, como se aprecia en el Gráfico 1 (Anexo), los cuatro usuarios que llegaron hasta el final opinaron que la arteterapia les ayudó a relajarse. Sus opiniones respaldaron los datos de la asistencia al confirmar que la arteterapia les apoyó bastante a continuar con el tratamiento. Sorprendieron, para tan pocas sesiones, las buenas puntuaciones dadas en autoconocimiento y autoconocimiento del propio problema. No representando uno de los temas de las sesiones significa, quizás, que sea ésta una cuestión transversal a todo el programa. En menor valoración, la exploración de las emociones. A la respuesta de si la arteterapia les ayudó a dejar de fumar los usuarios se muestran poco ilusionados pero, no obstante, uno de los cuatro indica que le ayudó bastante.

En último lugar, para completar el análisis se revisaron las funciones del arte (De Botton y Armstrong, 2013) tanto en las obras como durante los procesos creativos. Algunas de las imágenes reflejan funciones psicológicas del arte ${ }^{13}$ y apoyando las conexiones para la introducción del arte en la terapia psicológica de tabaquismo.

1. Memoria. El arte es un mecanismo que nos ayuda a recordar lo que nos importa y a preservar las experiencias. Así ocurrió en la última sesión mientras se revisaban las obras creadas por los usuarios a lo largo de todo el tratamiento. También se observó en el transcurso del tratamiento. En su primera obra (Imagen 1), una mujer dibujó un recorrido ondulante alternando dos colores, rojo y azul. Ella se situaba en el rojo pues había tenido una recaída después de 5 años sin fumar pero sabía donde quería regresar y añadió un último trazo azul... Abandonaría dejando el grupo a la mitad de su recorrido.

13 De las 7 funciones del arte descritas por los autores se han comentado 5 de ellas localizadas a posteriori sobre los registros y las obras. 


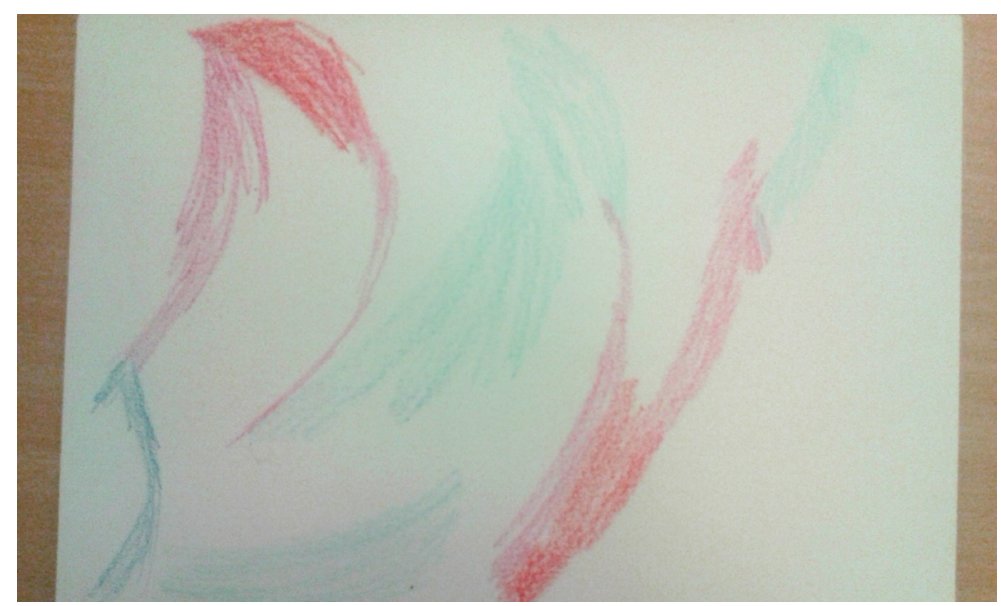

Imagen 1. Representación de la historia vital en su relación con el tabaco describiendo distintas etapas representadas mediante el código del color.

2. Reequilibrio. El arte pone ante nuestros ojos lo que necesitamos, es una forma de "reequilibrio emocional". Por ejemplo, otro usuario identificó en un árbol su relación vital con el tabaco (Imagen 2). Decía que poco a poco había ido creciendo y las raíces se habían metido debajo de la casa. Sabía por otros amigos que al sacar las raíces podría dañarse la estabilidad de toda la casa. Lo que hicieron, contando con el apoyo familiar, fue cortarlo aun sabiendo que las raíces seguirían estando allí. Fue su última sesión de arteterapia. Al final del tratamiento esta persona, que continuaba en el grupo, había dejado de fumar e hizo contribuciones muy importantes para la evaluación.

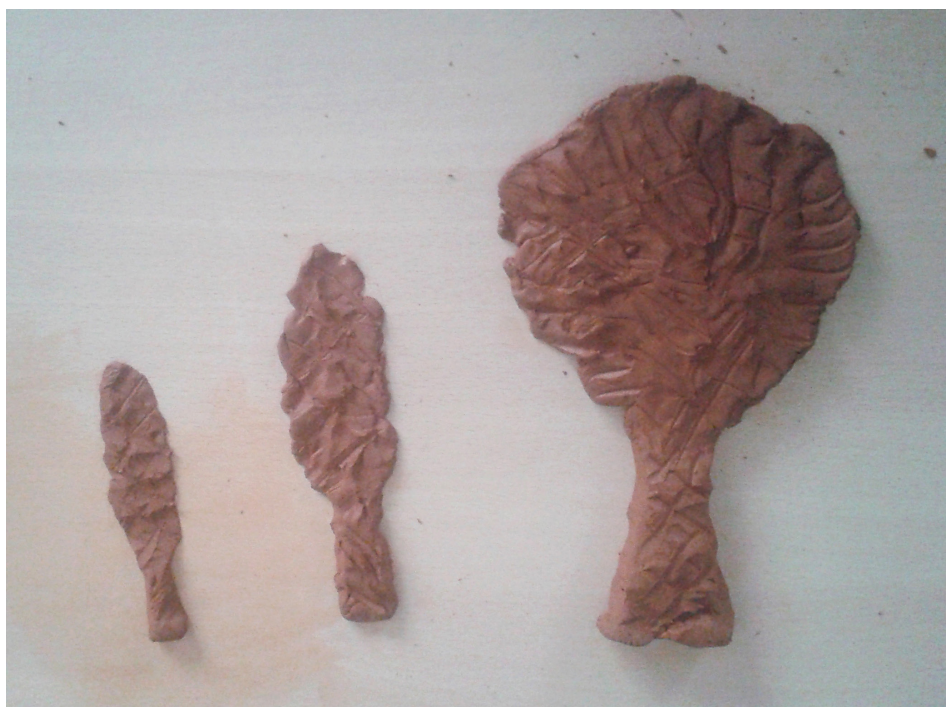

Imagen 2. Las raíces del árbol del tabaco. El arte da forma a las debilidades y ayuda a restaurar el equilibrio. 
3. Autoconocimiento. El arte recoge cosas en nuestro interior y nos ayuda a identificarlas y a expresarlas. Nos ofrece identidad: "conocernos a nosotros mismos y mostrar a otros como somos" (De Bottom y Armstrong, 2013). Para representar aspectos internos con una imagen-animal uno de los usuarios eligió el burro (Imagen 3). Cambiando la perspectiva -los miedos- y saliendo de su discurso negativo de obras anteriores logró ver las fortalezas en el burro que identificó consigo mismo. Utilzó aspectos positivos tales como la fuerza, la nobleza, y la limpieza.

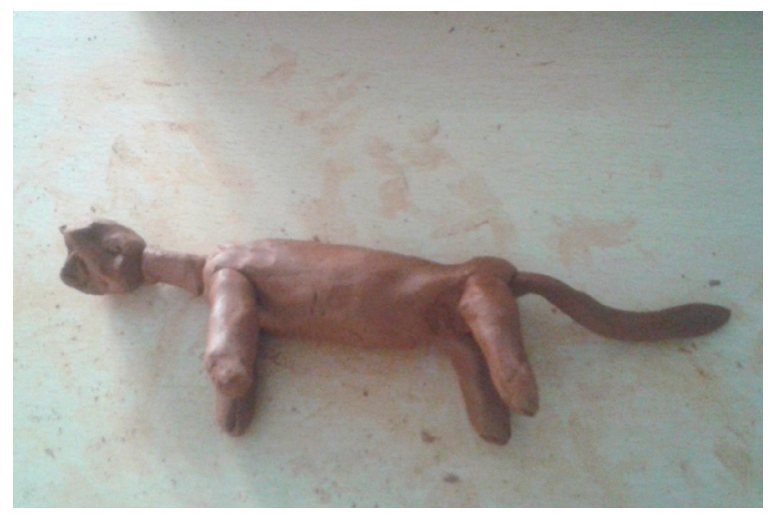

Imagen 3. El Burro. Identificación con la cualidades de un animal.

4. Esperanza. El arte permite generar consciencia de cómo debería ser la vida. La imagen, recurrente, enseña el camino hacia una vida idealizada, sin humos, sana y en la naturaleza junto a la familia (Imágenes 4). Un personaje épico que muestra el difícil recorrido en el pasado saliendo de un círculo vicioso dibujado en rojo y cómo lo ha ido abandonando hacia el lugar donde está su esperanza representada por su casa de campo en las afueras.

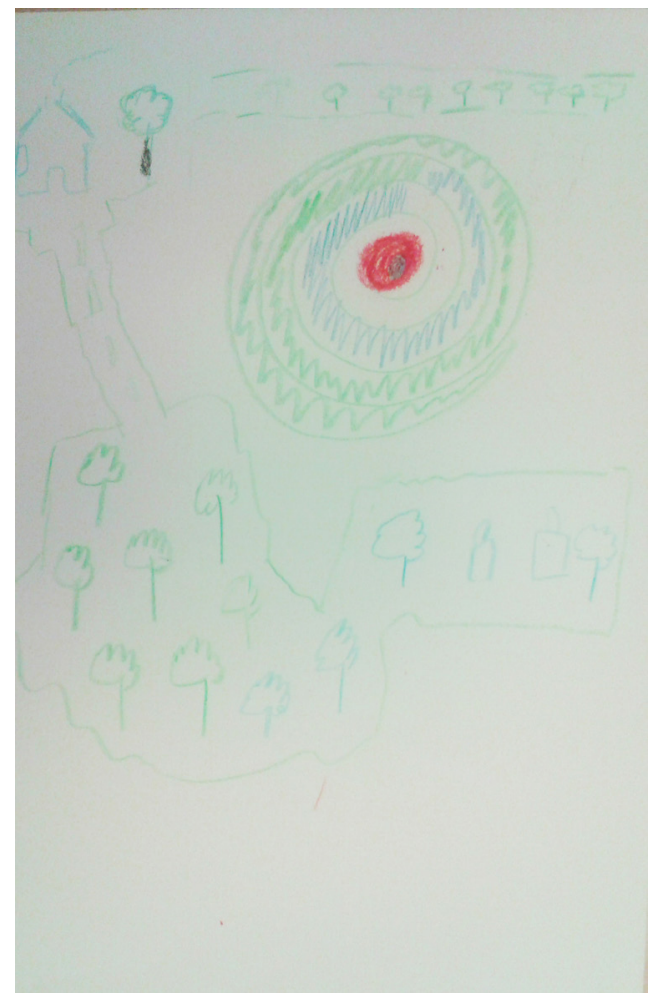

Imagen 4. Mapas y recorridos dibujados por un usuario representando su desarrollo vital y emocional durante sus años como fumador y cómo se ve a sí mismo en los próximos años.

5. Dolor dignificado. Sacar fuera la tristeza permite reconocerla. La saca de un vacío oscuro y la eleva, y el dolor se hace más pequeño cuando es compartido. Las imágenes hablan de una persona se que calificaría a sí misma como sola y pasiva. Destaca en ellas la monocromía y la crudeza de su expresividad (Imagen 5, arriba-izquierda). Sin embargo, reaccionó. Según avanzaban las sesiones se volvió hacia el grupo y consiguió utilizar este lenguaje propio en favor propio. 

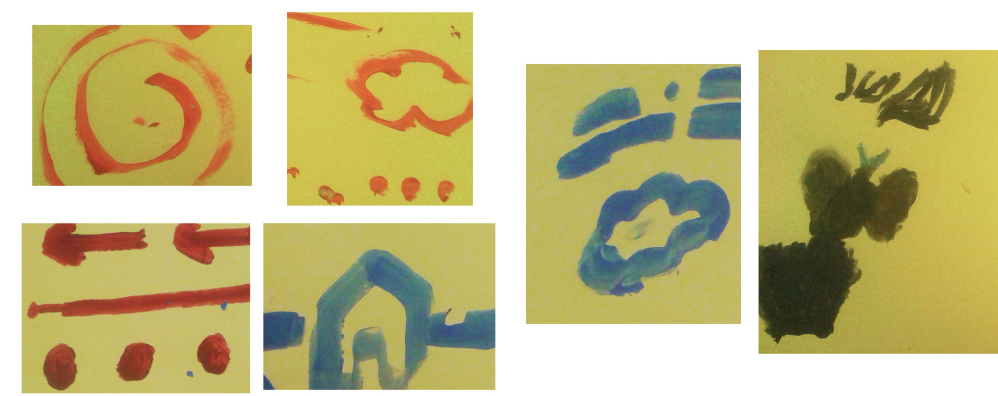

Imagen 5. Representaciones del mundo interno de algunos/as usuarios/as.

Nuevos lenguajes de marcas y signos gráficos.

La experiencia realizada y los resultados obtenidos invitan a ser optimistas, especialmente teniendo en cuenta la dificultad de estos tratamientos. Un seguimiento posterior al mes y a los tres meses indicó que las cuatro personas que finalizaron el tratamiento siendo parte también del grupo de arteterapia se mantenían sin fumar.

A modo de balance final, decir que se ha podido dar respuesta positivamente a la cuestión de la colaboración con los tratamientos de tabaco descubriendo, además, la arteterapia como un posible factor de adherencia. Además, esta investigación ha permitido acercarse a las funciones psicológicas del arte, en especial la autorreguladora, para su aplicación como herramienta de apoyo en el abordaje del tabaquismo.

\section{Agradecimientos}

Se merece un alto reconocimiento la ayuda prestada por el CMSc Latina del Ayuntamiento de Madrid y muy en especial a la supervisión de su directora, Dra. Mercedes Campillos Alonso. Mención a parte también para la colaboración del médico referente del programa, Dr. Pedro Martínez Urzay. Gracias a su apoyo, conocimientos, consejos, y persona.

\section{Referencias Bibliográficas}

Becoña, E. (2003). El tratamiento psicológico de la adicción a la nicotina. Papeles del psicólogo, 24 (85).

Becoña, E., Fernández del Río, E., López, A., Martínez, Ú., Martínez, C., y Rodríguez, R. A. (2014). El tratamiento psicológico de la dependencia del tabaco. Eficacia, barreras y retos para el futuro. Papeles del psicólogo, 35(3).

Becoña, E., Míguez, M, Fernández, López, A. (2010). Dependencia del tabaco. Manual de casos clínicos. En Elisardo Becoña (Coord). Madrid: Sociedad Española de Psicología Clínica, Legal y Forense.

Case, C. y Dalley, T. (2006). The handbook of art therapy. Routledge.

Czamanski-Cohen, J., Sarid, O., Huss, E., Ifergane, I., Niego, L. y Cwikel, J. (2014). CB-ARTThe use of hybrid cognitive behavioral and art based protocol for treating pain and symptoms acompanying coping with chronic illness. The Arts in Psychotherapy, 41, 320-328. 
De Bottom, A., y Armstrong, J. (2013). Art as therapy. Phaidon Press.

Fernández-Nuñez, L. (2006). ¿Cómo analizar los datos cualitativos? Butlletí LaRecerca Ficha 7.

Herrero, F. J., y Moreno, J. J. (2004). Tratamientos combinados del tabaquismo: psicológicos y farmacológicos. Adicciones, 16 (2), 287-320.

Kaplan, F. (2000). Art, science and art therapy: Repainting the picture. London: Jessica Kingsley Publishers.

de la Llave, A. L., Buceta, J. M., \& Pérez-Llantada, M. C. (2000). Evaluación de un programa de tratamiento psicológico para dejar de fumar: el efecto del feedback de CO. Revista de psicopatología y psicología clínica, 5(2), 131-144.

Liebmann, M. (2004). Art therapy for groups: A handbook of themes and exercises. Hove: Psychology Press.

López Fernández-Cao, M (1998). La retórica visual como análisis posible en la didáctica del arte y de la imagen. Arte, individuo y Sociedad 10.

López, M. D. (2009). La intervención arteterapéutica y su metodología en el contexto profesional español (Tesis, Universidad de Murcia). Consulta: junio de 2018. Disponible en https://digitum.um.es

Madrid Salud (2018). Por un Madrid sin tabaco ¿Te apuntas a dejar de fumar? Página de Salud Pública del Ayuntamiento de Madrid. Consultado en http://madridsalud.es/ prevencion-control-consumo-tabaco

Míguez, M. (2004). Los procedimientos de autoayuda para dejar de fumar. Adicciones, 16, Monografía Tabaco (2), 339-357.

Nucho, A. O. (2003). The psychocybernetic model of art therapy. ( $2^{\circ}$ ed). Sprinfield, Ilinois: Charles $\mathrm{C}$ Thomas Publisher.

Pardell, H. y Saltó, E. (2004). Beneficios de dejar de fumar. Adicciones, 16, Monografía Tabaco (2), 131-142.

Pénzes, I., van Hooren, S., Dokter, D., Smeijsters, H., y Hutschemaekers, G. (2014). Material interaction in art therapy assessment. The Arts in Psychotherapy, 41(5), 484-492.

Riley, S. (2013). Group process made visible: The use of art in group therapy. Philadelphia: Routledge.

Rosal, M. L. (2018) Cognitive-Behavioral Art Therapy: From Behaviorism to the Third Wave. Taylor and Francis. Edición de Kindle.

Rosales-Nieto, J. G., Moreno San Pedro, E., Córdoba García, R., Marín Romero, B., Jiménez López, F. R., Gil Luciano, A., ... Hernández-López, M. (2016). Flexibilidad psicológica y autoabandono del tabaco. International Journal of Psychology and Psychological Therapy, 16(2).

Rubin, J. A. (2005). Artful therapy. Hoboken, New Jersey: John Wiley \& Sons.

Salvador, T, Córdoba, R., Planchuelo, M.A., Nebot, M., Becoña, E, Barrueco, M., y Riesco, J. A. (2005). Usted puede dejar de fumar: Las claves para conseguirlo. Ministerio de Sanidad y Consumo y Comité Nacional para la Prevención del Tabaquismo (Eds.). Extraído de http://www.cnpt.es

Tashakkori, A., y Teddlie, C. (1998). Mixed methodology: Combining qualitative and quantitative approaches. Thousand Okas, California: Sage

Valles, M.S. (1999). Técnicas cualitativas de investigación social: Reflexión metodológica y práctica profesional. Madrid: Síntesis Editorial. 


\section{ANEXO}

Tabla 1. Análisis de texto libre, tradición narrativa de metodología cualitativa (Fernández Nuñez, 2006), a partir del diario de campo de las sesiones de arteterapia.

Categorías inspiradas en Rubin (2005, pp. 51-66).

\section{$\underline{\text { Temas }}$}

- No se observaron grandes dificultades para entender las propuestas.

- Ofrecer varias opciones funciona mejor que ofrecer una propuesta única.

- Abordar ciertos temas podría producir demasiada intensidad especialmente en las últimas sesiones.

\section{Procesos}

- Aprendizajes.

- Nuevas perspectivas y otros lenguajes.

- Creatividad y solución de problemas.

- Perfeccionismo, necesidad de control.

\section{Participación}

- Participaciones en arteterapia y grupo de tabaco.

- Lograr dejar de fumar participando en arteterapia.

- Abandonos inesperados y descenso de la implicación.

\section{Materiales}

- Manejabilidad.

- Controlabilidad.

- Familiaridad.

- Aquellos que no requieren excesiva técnica.

\section{Obras}

- Abstracción, representación, simbolismo y metáfora.

- Recorridos o mapas.

- Poca estima hacia la calidad de lo creado.

\section{$\underline{\text { Desarrollo }}$}

- Cambios en la mirada hacia terapia.

- Conexión de unos temas con otros a lo largo de las sesiones.

- Preferencia a no profundizar en asuntos personales e íntimos.

Tabla 2. Registro de asistencia a las sesiones: Grupo = Grupo de Tabaco; $\mathrm{AT}=$ Grupo de Arteterapia.

\begin{tabular}{|l|c|c|c|c|c|c|c|c|c|c|}
\hline SESIÓN & 1 & 2 & 3 & 4 & 5 & 6 & $\mathbf{7}$ & 8 & 9 & S \\
\hline GRUPO & 8 & 10 & 11 & 8 & 8 & 6 & 4 & 3 & 4 & 3 \\
\hline AT & - & $\mathbf{5}$ & $\mathbf{7}$ & $\mathbf{3}$ & $\mathbf{5}$ & $\mathbf{4}$ & $\mathbf{2}$ & $\mathbf{1}$ & $\mathbf{4}$ & $\mathbf{3}$ \\
\hline
\end{tabular}


Gráfico 1. Respuestas de 4 usuarios (n) al cuestionario de evaluación de 9 sesiones de arteterapia en un programa de deshabituación tabáquica.

$$
\mathrm{n} 1 \mathrm{n} 2 \mathrm{n} 3 \mathrm{n} 4
$$

Satisfacción de las expectativas Ayuda para seguir en el grupo de tabaco

Autoconocimiento de mi problema

Estrategias de afrontamiento

Relajación

Comprensión de las emociones

Autoconocimiento

Dejar de fumar
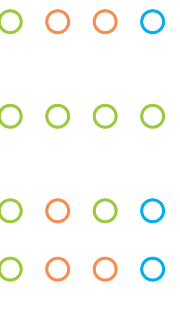

000

0000

0000

$\bigcirc \bigcirc \bigcirc \bigcirc$

Escala Likert de 1 a 4. $\circ$ Nada $\circ$ Poco $\circ$ Bastante $\circ$ Mucho 